ISSN 1112-9867

http://www.jfas.info

\title{
MODELING THE POTENTIAL IMPACTS OF GLOBAL CLIMATE CHANGE IN BANGLADESH: AN OPTIMAL CONTROL APPROACH
}

\author{
H. A. Biswas ${ }^{1, *}$, T. Rahman ${ }^{2}$ and N. Haque ${ }^{3}$ \\ ${ }^{1}$ Mathematics Discipline, Khulna University, Khulna-9208, Bangladesh \\ ${ }^{2}$ Department of CSE, Jessore University of Science and Technology, Jessore, Bangladesh \\ ${ }^{3} \mathrm{PhD}$ Fellow, Department of Economics, Islamic University, Kustia, Bangladesh
}

Received: 27 April 2015 / Accepted: 30 October 2015 / Published online: 01 January 2016

\begin{abstract}
One of the hottest issues in the recent environmental research worldwide has become the harmful effects of climate change on the ecosystems and environment due to global warming. Bangladesh is one of the most vulnerable countries not only in the South East Asia but also in the world. It is predicted that a large portion of the South-western region of Bangladesh will go under sea in the next 50 to 100 years due to sea level rise. In this paper, we first discuss some potential impacts of climate change in Bangladesh and its aftermath on the ecosystems and secondly, we study a mathematical model of climate change in terms of ordinary differential equations (ODEs) and apply optimal control techniques in the form of Pontryagin Maximum Principle (PMP) to investigate the control strategy of greenhouse gases (GHGs). We study the model numerically using some known nonlinear 'optimal control solvers' and the results are illustrated with numerical simulations.
\end{abstract}

Keywords: mathematical model; climate change; ecosystems; harmful effects;optimal control.

Author Correspondence, e-mail: mhabiswas@yahoo.com

doi: http://dx.doi.org/10.4314/jfas.v8i1.1 


\section{INTRODUCTION}

Now-a-days Climate change due to global warming is a reality and no longer a future concern. Many adverse effects of climate change stimuli including variability and extreme are already visible. In 1990, Intergovernmental Panel on Climate Change (IPCC) estimates that with a business-as-usual scenario of greenhouse gas emission, the world would be $3.3^{\circ} \mathrm{C}$ warmer by the end of the $21^{\text {st }}$ century, with a range of uncertainty of 2.2 to $4.9^{\circ} \mathrm{C}$ (Sarwar, 2005). So there is no dought that we are presently experiencing progressive global warning due to the increased production of 'greenhouse gasses' (Zell, 2004). Various human activities are making the world hot to hotter. Since the beginning of the 19th century, the industrial era has produced an increasing amount of $\mathrm{CO} 2$. The evolution of $\mathrm{CO} 2$ concentration in the atmosphere during the last decades has been extremely important and the ultimate result is global warming, i.e. climate change (Geri et al., 2014). Rising temperature in the atmosphere causes sea level rise and affects low lying coastal areas and deltas of the world. Today, our world is $0.8^{\circ} \mathrm{C}$ above pre-industrial levels of the 18 th century. We could see a $2^{\circ} \mathrm{C}$ world in the space of one generation (World Bank, 2013). As global warming climbs from present levels of $0.8^{\circ} \mathrm{C}$ up to $1.5^{\circ} \mathrm{C}, 2^{\circ} \mathrm{C}$ and $4^{\circ} \mathrm{C}$ above pre-industrial levels, this result is a dramatic picture of a world of climate and weather extremes causing devastation and human suffering. In many cases, multiple threats of increasing extreme heat waves, sea-level rise, more severe storms, droughts and floods will have severe negative implications for the poorest and most vulnerable like Bangladesh (IPCC, 2014).

Bangladesh is already vulnerable to many gradual change phenomena of climate change as well as climate change related extreme events. It is expected that climate change will bring changes in characteristics of gradual change phenomenon and natural hazards which will result changes in physical, social and production system. Studies and assessments on impacts, vulnerabilities and adaptation to climate change and sea level rise for Bangladesh clearly demonstrate that Bangladesh is one of the most climate vulnerable countries in the world. Rainfall is predicted to become higher and more erratic. Frequency and intensity of natural disasters are likely to increase especially in the northern and western part of the country. Several early evidences of the above phenomenon and its associated impacts in the agriculture, 
health, water and sanitation, biodiversity are already visible in Bangladesh. Overall impacts of climate change on Bangladesh would be significant. It is estimated that climate change could affect more that 70 million people of Bangladesh due to its geographic location, low elevation, high population density, poor infrastructure, high levels of poverty and high dependency on natural resources. It was found that the population living in the coastal area is more vulnerable than the population in other areas (Alam and Murray, 2005). Coastal resources upon which the most people depend are likely to be affected severally due to climate variability and change. It is predicted that for $45 \mathrm{~cm}$ rise of sea level may inundate $10-15 \%$ of the land by the year 2050 resulting over 35 million climate refugees from the coastal districts. Ultimately adverse impacts have the potential to undermine poverty reduction efforts and could compromise the Millennium Development Goals (MDGs), such as the eradication of poverty and hunger by 2015 (Policy Study, 2009). A schematic picture of likely sea level rises and its potential impacts on Bangladesh is shown in Figs. 1(a) and 1(b).

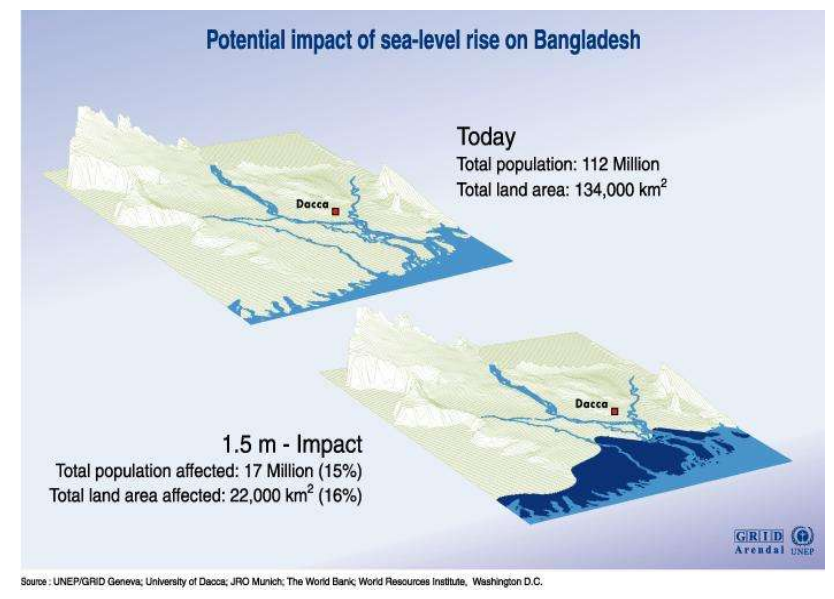

Fig. 1(a): Potential impacts of 1.5 meter sea level rise on Bangladesh due to climate change (Source: UNEP, 1989). 


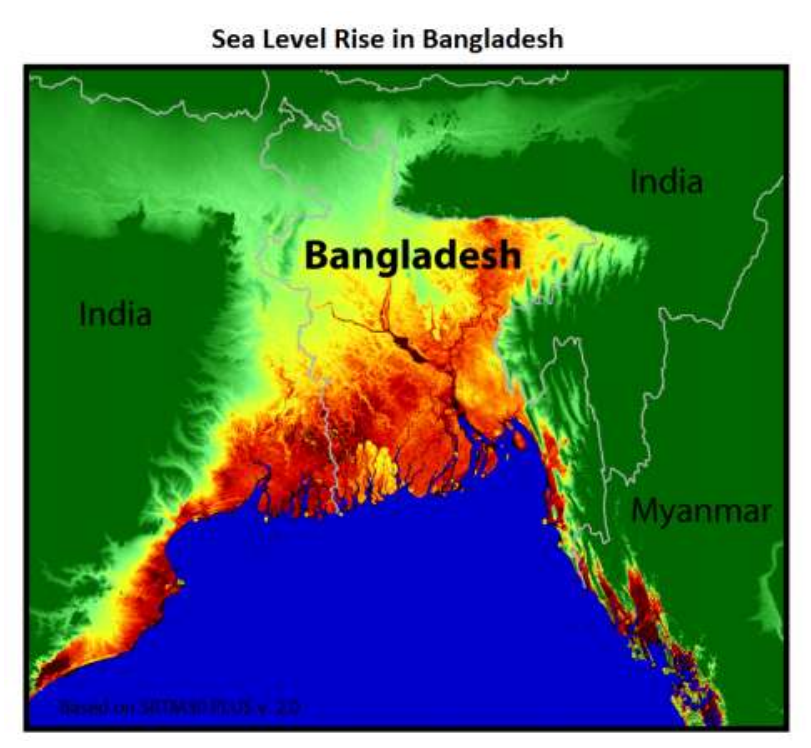

Fig. 1(b). Schematic picture of likely sea level rises in Bangladesh at the end of $21^{\text {st }}$ century.

Over the last decade several studies have been conducted on climate change impacts, vulnerability and adaptation assessments for Bangladesh using different climate change scenarios. Most of the studies focus on water, agriculture, biodiversity, human health, and infrastructure (Policy Study, 2009; Alam and Murray, 2005; Sarwar, 2005). However, research on mathematical modeling of climate change for obtaining better strategy of sustainable managements of our ecosystems is not well explored. Our aim in this paper is mainly to formulate the dynamics of a climate change in a mathematical model in the form of ordinary differential equations. We solve the model by numerically and then analyze the nonlinear behavior of the climate dynamics. An optimal control strategy for the sustainable management of the concentration of greenhouse gas emissions and the average surface temperature on the earth is discussed with numerically simulated data.

\section{A MODEL OF CLIMATE CHANGE}

Nonlinear phenomena characterize all aspects of global change dynamics, from the Earth's climate system to human decision-making. The Earth's climate system is highly nonlinear and complex, that is, the inputs and outputs are not proportional and change is often episodic and abrupt, rather than slow and gradual, and multiple equilibria are the norm (Rial et al., 2004). The Earth's climate system includes the natural spheres (e.g., atmosphere, biosphere, 
hydrosphere and geosphere), the anthrosphere (e.g., economy, society, culture), and their complex interactions (Schellnhuber, 1999). These interactions are the main source of nonlinear behavior, and thus one of the main sources of uncertainty in our attempts to predict the effects of global environmental change. Past records of climate change are perhaps the most frequently cited examples of nonlinear dynamics, especially where certain aspects of climate suggest the existence of thresholds, multiple equilibria, and other features that may result in episodes of rapid change (Rial et al., 2004). However, these nonlinear phenomena of rapid change in the earth's climate systems can be captured and modeled by the nonlinear ordinary differential equations (NODEs) in the form of mathematical modeling. In recent years, mathematical models have become the most important tools in analyzing the dynamics of environmental, ecological as well as biological and biomedical systems. An efficient and sustainable management of natural recourses and their control measure of such systems mainly depends on an essential understanding the mechanisms of their evolution. Mathematical models can provide better insights of their complex and nonlinear mechanisms which lead to design better prediction, prevention, management and control programs. Numbers of mathematical models for different biological and environmental systems have been proposed and investigated by several authors over the years. We refer readers to (Biswas, 2014; Patz and Olson, 2006; Nordhaus, 1992; Biswas, et.al., 2014; Agarwal and Verma, 2012; Rodrigues et. al., 2010) for more detailed discussions on some of the recent mathematical models of different environmental, biological and biomedical systems.

We consider a simple dynamic growth model of climate change with three state variables; Capital (per capita) $K(t), C O 2$ concentration in the atmosphere $M(t)$ and global average surface temperature (in Kelvin) $T(t)$ and two control variables; consumption $C(t)$ and Abatement per capita $A(t)$. We are mainly concern with the current state of the knowledge concerning GHG emissions and the change in global average surface temperature. The simplest method of considering the climate system of the earth is in terms of its global energy balance which is done by so-called energy balance models (EBM). According to an EBM the change in the average surface temperature on earth is described by the ordinary differential 
equation

$$
\begin{aligned}
& \frac{d \dot{T}(t)}{d t} c_{h}=S_{E}-H(t)-F_{N}(t) \\
& T(0)=T_{0},
\end{aligned}
$$

where $c_{h}$ is the heat capacity of the earth with dimension $J^{-2} K^{-2}$ (Joule per square meter per Kelvin) which is considered a constant parameter, $S_{E}$ is the solar input, $H(t)$ is the non-radiative energy flow, and $F_{N}(t)=F \uparrow(t)-F \downarrow(t)$ is the difference between the outgoing radiative flux and the incoming radiative flux. $S_{E}, H(t)$ and $F_{N}(t)$ have the dimension Watt per square meter $\left(W^{-2}\right) . t$ is the time argument which will be omitted in the following as long as no ambiguity can arise. The outgoing radiative flux $F \uparrow(t)$ follows the Stefan-Boltzman law,

$$
F \uparrow=\in \sigma_{T} T^{4}
$$

where $\in$ is the emissivity which gives the ratio of actual emission to blackbody emission. We recall that blackbodies are objects which emit the maximum amount of radiation and which have $\in=1$. For the earth, $\in$ can be set to $\in=0.95 . \sigma_{T}$ is the Stefan-Boltzmann constant. Further, the difference $S_{E}-H(t)$ can be written as

$$
S_{E}-H=\frac{Q}{4}\left(1-\alpha_{1}(T)\right)
$$

$Q$ is the solar constant, $\alpha_{1}(T)$ is the planetary albedo at temperature $T$, determining how much of the incoming energy is reflected to space. The albedo $\alpha_{1}(T)$ is a function which negatively depends on the temperature on earth. This holds because deviations from the equilibrium average surface temperature have feedback effects which affect the reflection of incoming energy. Examples for such feedback effects are the ice-albedo feedback mechanism and the water vapour 'greenhouse' effect (see [8], chap. 1.4). However, the albedo (non-reflected energy) at temperature $T$ is defined as the differentiable function.

$$
\left(1-\alpha_{1}(T)\right)=k_{1} \frac{2}{\pi} \arctan \left(\frac{\pi(T-293)}{2}\right)+k_{2}
$$


where $k_{1}$ and $k_{2}$ are parameters.

The effect of emitting GHGs is to raise the concentration of GHGs in the atmosphere which increases the greenhouse effect of the earth. This is done by calculating the so-called radiative forcing which is a measure of the influence a GHG, like $\mathrm{CO} 2$ or $\mathrm{CH} 4$, has on changing the balance of incoming and outgoing energy in the earth-atmosphere system. The dimension of the radiative forcing is $\mathrm{Wm}^{-2}$. For example, for $\mathrm{CO} 2$ the radiative forcing, which we denote as $F$, is given by

$$
F=6.3 \log \frac{M}{M_{o}}
$$

where $M$ is the actual $C O 2$ concentration and $M_{o}$ is the pre-industrial $C O 2$ concentration. Now, incorporating (2) - (5) in (1), we rewrite the dynamics of temperature $T$,

$$
\begin{aligned}
& \frac{d \dot{T}(t)}{d t} c_{h}=\frac{Q}{4}\left(1-\alpha_{1}(T(t))\right)-\in \sigma_{T} T(t)^{4}+\beta_{1}(1-\xi) 6.3 \log \frac{M(t)}{M_{o}} \\
& T(0)=T_{0},
\end{aligned}
$$

The parameter $\xi$ captures the fact that $\xi=0.3$ of the warmth generated by the greenhouse effect is absorbed by the oceans which transport the heat from upper layers to the deep sea. $\beta_{1}$, finally, is assumed to take values between 1.1 and 3.4 and takes into account that with a higher GHG concentration and, consequently, a higher temperature on earth the ability of oceans to absorb warmth is reduced.

As concerns emissions of GHGs we assume that these are a by-product of capital used in production and expressed in $\mathrm{CO} 2$ equivalents. So emissions are a function of per capita capital relative to per capita abatement activities. It should also be mentioned that the emission of GHGs does not affect utility and production directly but only indirectly by affecting the climate of the earth which leads to a higher surface temperature and to more extreme weather situations. Formally, emissions are described by

$$
E=\left(\frac{a K}{A}\right)^{\gamma}
$$

where $\gamma>0$ and $a>0$ are constants. The parameter $a$ can be interpreted as a technology 
index describing how polluting a given technology is. Now, the concentration of GHGs $M$, evolves according to the following differential equation,

$$
\begin{aligned}
& \frac{d M(t)}{d t}=\beta_{2} E-\mu M(t) \\
& M(0)=M_{0},
\end{aligned}
$$

where $E$ denotes emissions as in (6) and $\mu$ is the inverse of the atmospheric lifetime of $C O 2$. As to the parameter $\mu$, we assume a value of $\mu=0.1 . \beta_{2}$ Captures the fact that a certain part of GHG emissions are taken up by oceans and do not enter the atmosphere.

An economy of a country is considered where one homogeneous good is produced. Further, the economy is represented by one individual with household production who maximizes a discounted stream of utility arising from per capita consumption, $C$, times the number of household members subject to a budget constraint. As to the utility function we assume a logarithmic function, $U(C)=\log C$.

Then the dynamics of per capita capital $K$ in terms of individual's budget constraint is given by,

$$
\begin{aligned}
& \frac{d K(t)}{d t}=Y-C-A-\tau_{E} E L^{-1}-(\delta+n) K(t) \\
& K(0)=K_{0},
\end{aligned}
$$

where $Y$ is per capita production, $A$ per capita abatement activities and $E$ emissions. $\tau \in(0,1)$ is the income tax rate, $\tau_{E}>0$ is the tax on emission, $\delta$ is the depreciation rate of capital. $L$ is labour which grows at rate $n$. The production function is given by

$$
Y=B K^{\alpha} D\left(T-T_{o}\right)
$$

where $\alpha \in(0,1)$ is the capital share, $B$ is a positive constant and $D\left(T-T_{o}\right)$ is the damage due to deviations from the normal temperature $T_{o}$. The damage function is defined as

$$
D\left(T-T_{o}\right)=\left(a_{1}\left(T-T_{o}\right)^{2}+1\right)^{-\psi}
$$

where $a_{1}>0$ and $\psi>0$ are constants. Using (10) and (11) in (9), we take the dynamics of per capita capital $K$ as the following ordinary differential equation, 


$$
\begin{aligned}
& \frac{d K(t)}{d t}=B K^{\alpha}\left(a_{1}\left(T-T_{o}\right)^{2}+1\right)^{-\psi}-C-A-\tau_{E} E L^{-1}-(\delta+n) K(t) \\
& K(0)=K_{0},
\end{aligned}
$$

where $C(t)$ and $A(t)$ are two control variables representing the consumption and abatement per capita respectively and the controls are constrained as

$$
0<C(t) \leq C_{\max }=1, \forall t \in\left[0, t_{f}\right] \quad \text { and } \quad A_{\min } \leq A(t) \leq A_{\max }, \forall t \in\left[0, t_{f}\right] .
$$

Here $A_{\min }$ and $A_{\max }$ are set to $7 \times 10^{-4}$ and $3 \times 10^{-3}$ respectively. Also, the state variables are constrained as

$$
M(t) \leq M_{\max }, \forall t \in\left[0, t_{f}\right] \text { and } T(t) \leq T_{\max }, \forall t \in\left[t_{s}, t_{f}\right]
$$

In most management science and environmental and economic problems, the objective function is usually formulated in money or utility terms. The future streams of money or utility are usually discounted (Sethi and Thompson, 2000). From this point of view, let us assume a constant continuous discount rate $\rho>0$, In the discounted objective function, it is usually assumed that the time dependence of the relevant functions comes only through the discount factor. So considering our problem as the finite horizon time problem, the discounted objective function can now be chosen as to maximize the consumption over a fixed final time as

Maximize $J(C, A)=\int_{0}^{t_{f}} e^{-(n-\rho) t} \log (C(t)) d t$

\section{CHARACTERIZATION OF OPTIMAL CONTROL MODEL}

Taking (6), (8), (12) and (15) into account, it is easy to see that our proposed model can be reformulated in the following optimal control form:

$$
(P)\left\{\begin{array}{l}
\text { Maximize } \int_{0}^{t_{f}} L(x(t), u(t)) d t \\
\text { subject to } \\
\dot{x}(t)=f(x(t), u(t)) \text { a.e. } t \\
u(t) \in U \text { a.e. } t \\
x(0)=x_{0}
\end{array}\right.
$$

where the functions are

$x(t)=(T(t), M(t), K(t)), \quad L(x, u)=e^{-(n-\rho) t} \log (C(t))$, 


$$
\begin{aligned}
& f(x, u)=\left(\begin{array}{l}
\frac{Q}{4}\left(k_{1} \frac{2}{\pi} \arctan \left(\frac{\pi(T-293)}{2}\right)+k_{2}\right)-\in \sigma_{T} T(t)^{4}+\beta_{1}(1-\xi) 6.3 \log \frac{M(t)}{M_{o}}, \beta_{2} E-\mu M(t), \\
B K^{\alpha}\left(a_{1}\left(T-T_{o}\right)^{2}+1\right)^{-\psi}-C-A-(\delta+n) K(t)
\end{array}\right), \\
& u(t) \in U=(C(t), A(t)) \text { and } x(0)=\left(T_{0}, M_{0}, K_{0}\right) .
\end{aligned}
$$

Now the problem $(P)$ is an optimal control problem. The necessary conditions of optimality for $(P)$ can be obtained by applying the well-known Pontryagin Maximum Principle (Pontryagin et al., 1962) for optimal control problem. In vein of (Vinter, 2000), the necessary conditions give closed forms for the controls (taking into account the control constraints) of our problem. One of the key issues in dealing with the optimal control problems is to ensure the existence of optimal solution of such problems before proceeding further analysis. However, it is worth mentioning that our problem has a discounted cost and the solution of such problem is guaranteed by (Sethi and Thompson, 2000). For the necessary conditions of optimality, we now define the current-value Hamiltonian as

$$
\begin{aligned}
H(T, M, K, C, A, p)= & \log C+p_{T}\left[\frac{Q}{4}\left(k_{1} \frac{2}{\pi} \arctan \left(\frac{\pi(T-293)}{2}\right)+k_{2}\right)-\in \sigma_{T} T(t)^{4}+\beta_{1}(1-\xi) 6.3 \log \frac{M(t)}{M_{o}}\right] \\
& +p_{M}\left(\beta_{2} a^{\gamma} K^{\gamma} A^{-\gamma}-\mu M(t)\right)+p_{K}\left(B K^{\alpha}\left(a_{1}\left(T-T_{o}\right)^{2}+1\right)^{-\psi}-C-A-(\delta+n) K(t)\right)
\end{aligned}
$$

Suppose that $\left(x^{*}, u^{*}\right)$ is the optimal solution of the problem $(P)$. The maximum principle in (Vinter, 2000) asserts the existence of an absolutely continuous function $p$ and a scalar $\lambda \geq 0$ such that

(i) $|p|+\lambda>0$,

(ii) $(-\dot{p}(t), 0)=p(t) \cdot f_{x, u}(x *(t), u *(t))-\lambda L_{x, u}(x *(t), u *(t))$,

(iii) $\forall u \in U, p(t) \cdot f\left(x^{*}(t), u *(t)\right)-\lambda L\left(x^{*}(t), u^{*}(t)\right) \geq p(t) \cdot f\left(x^{*}(t), u(t)\right)-\lambda L\left(x *(t), u^{*}(t)\right)$ a.e.,

together with the limiting transversality condition

$p\left(t_{f}\right)=\lim _{x \rightarrow \infty} e^{-(\rho+n) t}\left(p_{T} T+p_{M} M+p_{K} K\right)=(0,0,0)$.

Here $p(t)=\left(p_{T}, p_{M}, p_{K}\right)$ are the adjoint variables with respect to the state variables $(T, M, K)$ which are also known as the shadow prices of $T, M$ and $K$ respectively. However, we omit the detailed analytical analysis here. We now go for the numerical analysis and present the simulation results. 


\section{NUMERICAL RESULTS AND DISCUSSIONS}

We perform a numerical simulation to obtain the optimal vaccination schedules for our model. A nonlinear optimal control solver "ICLOCS" version 0.1b (Falugi, et al., 2010) written in programming language 'MATLAB' for solving the optimal control problems using 'IPOPT' solver is used as a tool. ICLOCS is an optimal control interface, implemented in Matlab, for solving the optimal control problems with general path and boundary constraints and free or fixed final time. ICLOCS uses the IPOPT - Interior Point OPTimizer - solver which is an open-source software package for large scale nonlinear optimization.

Considering a time interval of 100 years, a time-grid with 1000 nodes was created, that is, for $t \in[0,100]$ we get $\Delta t=0.1$. According to (Greiner, et al., 2010), the widely approved values for all parameters and constants are presented in Table 1. Since we used a direct method and, consequently, a iterative approach, we imposed an acceptable convergence tolerance at each step of $\varepsilon_{\text {rel }}=10^{-9}$. We take the initial values of the state variables as $T(0)=294.5, M(0)=2.0, K(0)=1.4$ and the control variables take values in $C(t) \in[0,1]$ and $A(t) \in\left[7.10^{-4}, 3 \cdot 10^{-3}\right]$ for all $t \in[0,100]$. We also take the terminal state constraints as $T\left(t_{f}\right)=291, M\left(t_{f}\right)=1.8, K\left(t_{f}\right)=1.4$. All other values of parameters and constants used to solve this model are taken as in (IPCC, 2014 and Greiner, et al., 2010) and are summarized in Table 1. We run the program using 'ICLOCS' and find the optimal solution with the values of objective functional 328.4916 at the computation time $71.4953 \mathrm{sec}$. The obtained results for optimal trajectories of states and controls are presented in Figs. 2 and 3 respectively.

From the Fig. 2, it is easy to observe that the per capita Capital $K(t)$ is increasing from the very beginning and after 20 years, it is gradually decreasing until at the end of 100 years, on the other hand, the CO2 concentration in the atmosphere $M(t)$ is decreasing gradually, although it increases a bit at the end and the global average surface temperature $T(t)$ decreases dramatically until 80 years, then it increases at the end, but all trajectories follow the terminal state constraints $T\left(t_{f}\right)=291, M\left(t_{f}\right)=1.8, K\left(t_{f}\right)=1.4$ at the end of 100 years. 

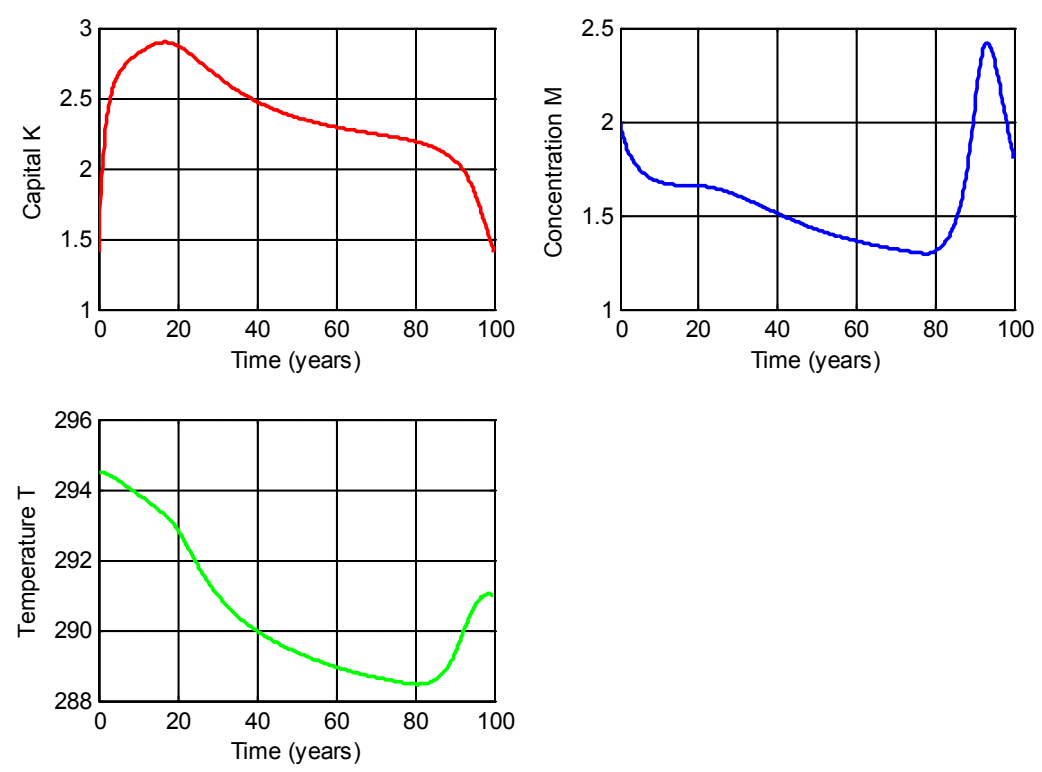

Fig. 2. Optimal state trajectories for per capita Capital $K(t), C O 2$ concentration in the atmosphere $M(t)$ and global average surface temperature $T(t)$ along with the terminal state constraints

In case of control trajectories, we can observe from Fig. 3 that both controls show singular behavior and optimal consumption $C(t)$ attains its maximum i.e., 1 at the end of 100 years which follows our objectives. Also, the per capita Abatement $A(t)$ attains its maximum from the beginning and during 78 to 90 , it goes down and then increases gradually attaining its maximum at the end of 100 years. 

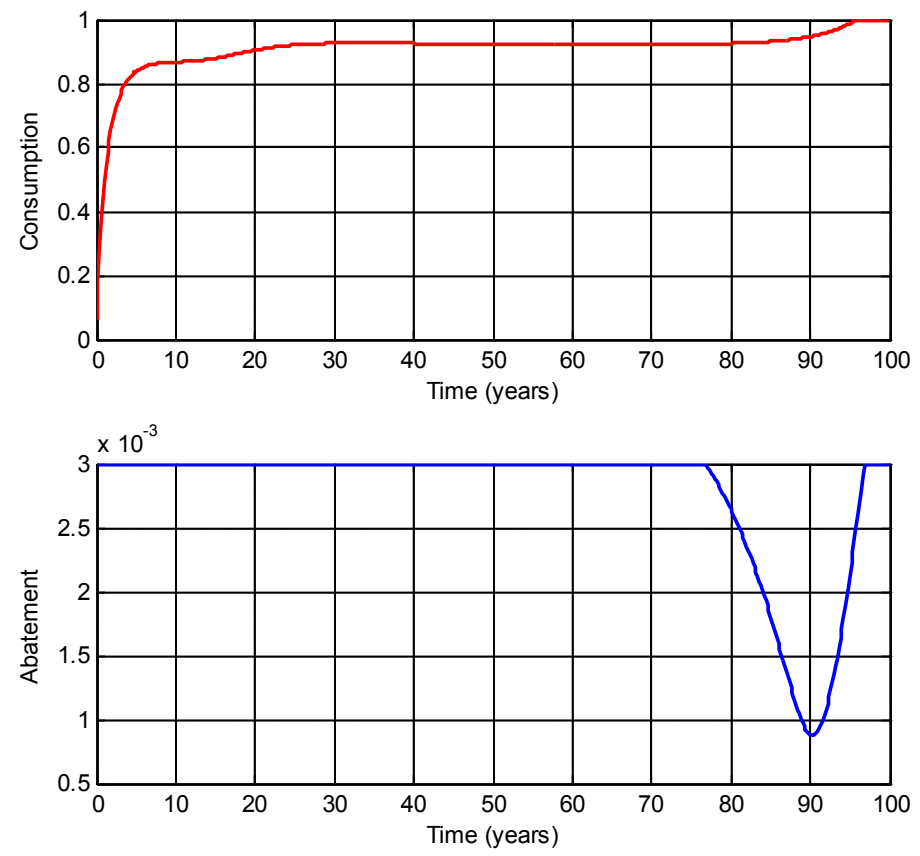

Fig. 3. Optimal control trajectories for the consumption $C(t)$ and per capita Abatement $A(t)$ along with the terminal state constraints 
Table 1. Description of parameters and constants and their values (Greiner, et al., 2010)

\begin{tabular}{|c|c|c|}
\hline $\begin{array}{c}\text { Parameters and } \\
\text { Constants }\end{array}$ & Definition of Parameters & Values \\
\hline 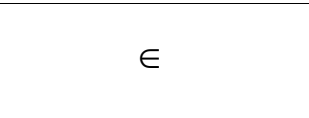 & $\begin{array}{l}\text { Ratio of actual emission to } \\
\text { blackbody emission }\end{array}$ & 0.95 \\
\hline$\sigma_{T}$ & Stefan-Boltzmann constant & $5.67 \times 10^{-8}$ \\
\hline$Q$ & The solar constant & 1367.5 \\
\hline$F \uparrow$ & The outgoing radiative flux & 109 \\
\hline$F \downarrow$ & The incoming radiative flux & 88 \\
\hline$\alpha_{1}$ & The planetary albedo & 5.0 \\
\hline$c_{h}$ & Heat capacity of the earth & 0.1497 \\
\hline$\beta_{1}$ & Constant & 1.1 \\
\hline$\beta_{2}$ & $\begin{array}{l}\text { GHG emissions taken up by } \\
\text { oceans }\end{array}$ & 0.49 \\
\hline$\delta$ & The depreciation rate of capital & 0.075 \\
\hline$\rho$ & The discount rate & 0.03 \\
\hline$n$ & The rate at which labor grows & 0.02 \\
\hline$k_{1}$ & Constant due to albedo & $5.6 \times 10^{-3}$ \\
\hline$k_{2}$ & Constant due to albedo & 0.2135 \\
\hline$a_{1}$ & The positive constant & 0.025 \\
\hline$\psi$ & The positive constant & 0.025 \\
\hline$\alpha$ & The capital share & 0.18 \\
\hline$\tau$ & The income tax rate & 0.15 \\
\hline$B$ & Positive constant & 0.35 \\
\hline$\gamma$ & Positive constant & 1 \\
\hline$\xi$ & Positive constant & 0.3 \\
\hline$T_{o}$ & Initial temperature & 293 \\
\hline
\end{tabular}

We now run the program to solve our model using the same initial conditions and the values of parameters but now discarding the terminal state constraints. The simulation results thus obtained for optimal trajectories of states and controls are presented in Figs. 4 and 5 respectively. 

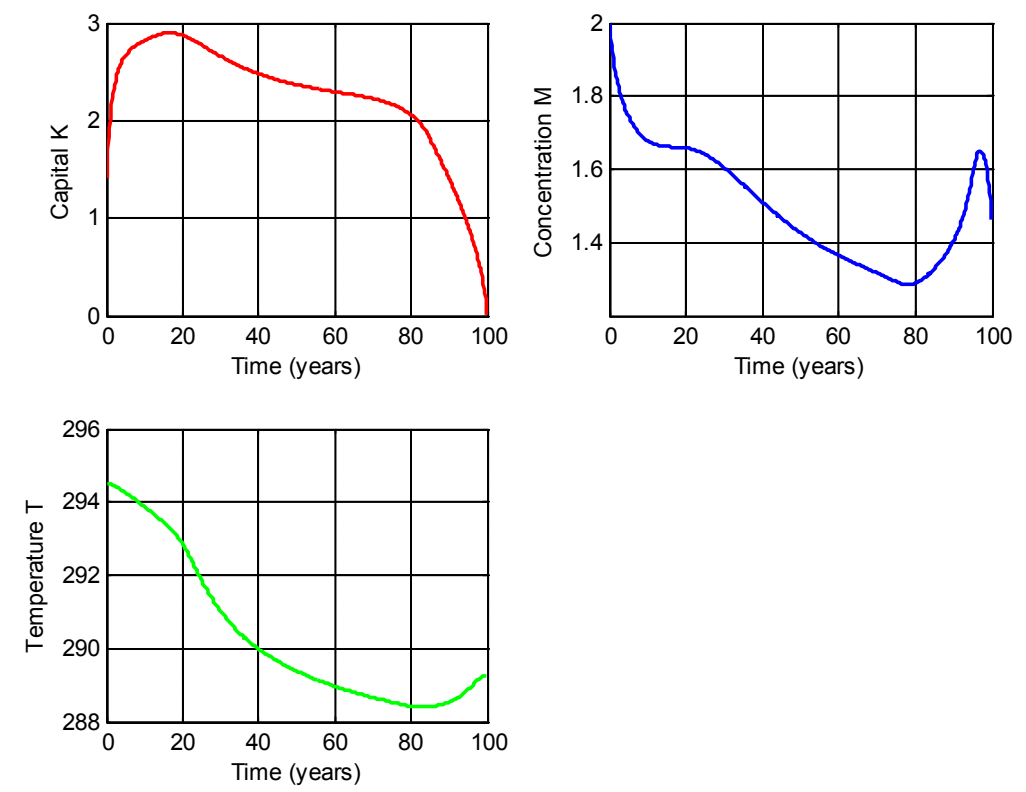

Fig. 4. Optimal state trajectories for per capita Capital $K(t), C O 2$ concentration in the atmosphere $M(t)$ and global average surface temperature $T(t)$ in absence of terminal state constraints
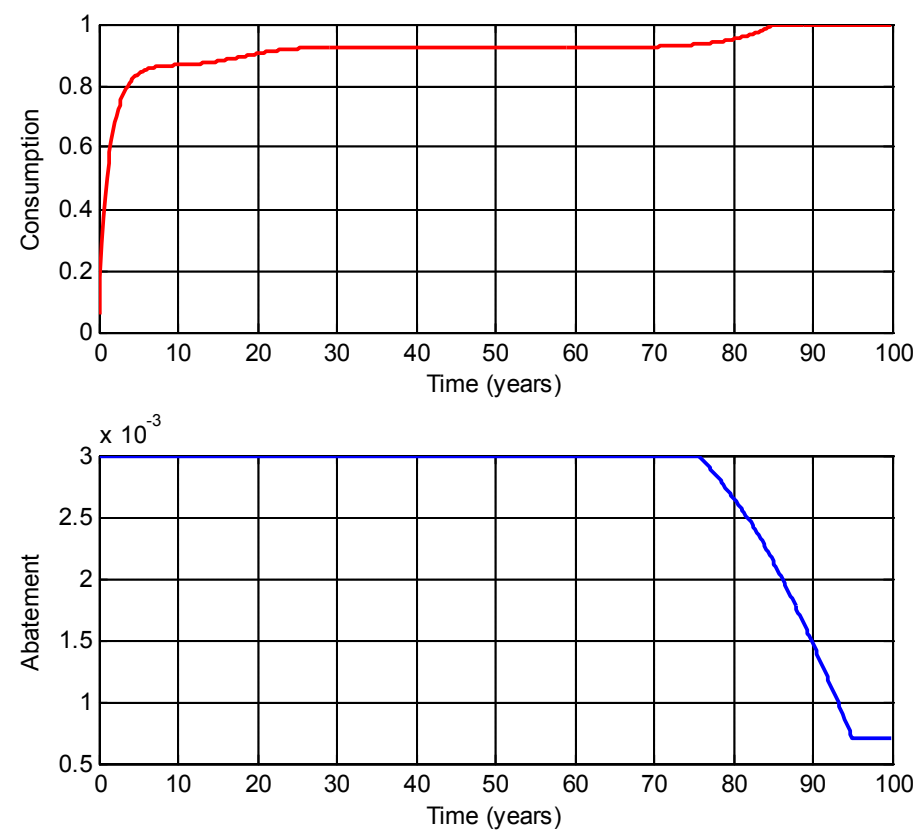

Fig. 5. Optimal control trajectories for the consumption $C(t)$ and per capita Abatement $A(t)$ in absence of terminal state constraints

In this case, 'ICLOCS' found the optimal solutions both for state and control trajectories with 
the objective functional value 256.9817. Fig. 4, shows that the per capita Capital $K(t)$ is increasing from the very beginning and after 20 years, it is gradually decreasing until at the end of 100 years approaching zero, on the other hand, the $\mathrm{CO}_{2}$ concentration in the atmosphere $M(t)$ is decreasing gradually and the global average surface temperature $T(t)$ decreases dramatically during almost the whole interval of time. For the control trajectories, Fig. 5 shows the similar singular behavior and optimal consumption $C(t)$ increases gradually and attains its maximum i.e., 1 at the end of 100 years. Also, the per capita Abatement $A(t)$ attains its maximum from the beginning and then decreases gradually at the end of 100 years.

\section{CONCLUSIONS}

Climate change is increasingly recognized as a major human security issue that poses serious global threats. Extreme weather phenomena such as floods, droughts, heat waves and cyclones, experienced in different parts of our globe, are among the far reaching consequences of climate change, giving us a bitter foretaste of what worse may come in the near future. Bangladesh is recognized worldwide as one of the countries most vulnerable to the impacts of global warming and climate change. This is due to its unique geographic location, dominance of floodplains, low elevation from the sea, high population density, high levels of poverty, and overwhelming dependence on nature, its resources and services. However, this 'man made global crisis' should be handled by a sustainable management of our ecological and environmental systems with adaption and mitigation. In this direction, an optimal control problem for the climate change has been studied in this paper in terms of mathematical modeling. A dynamic growth model with discounted cost functional for the climate change has been analyzed numerically and the simulation results have been illustrated with graphical representations.

\section{ACKNOWLEDGEMENTS}

The authors would like to extend their cordial thanks to the reviewers for the careful reading 
of this manuscript and their helpful comments which incorporate us to improve this revised manuscript.

\section{REFERENCES}

[1] World Bank, 2013. Turn Down the Heat: Climate Extremes, Regional Impacts, and the Case for Resilience. A report for the World Bank by the Potsdam Institute for Climate Impact Research and Climate Analytics. Washington, DC.

[2] IPCC, 2014: Climate Change 2014: Impacts, Adaptation, and Vulnerability. Part B: Regional Aspects. Contribution of Working Group II to the Fifth Assessment Report of the Intergovernmental Panel on Climate Change [Barros, V.R., C.B. Field, D.J. Dokken, M.D. Mastrandrea, K.J. Mach, T.E. Bilir, M. Chatterjee, K.L. Ebi, Y.O. Estrada, R.C. Genova, B. Girma, E.S. Kissel, A.N. Levy, S. MacCracken, P.R. Mastrandrea, and L.L. White (eds.)]. Cambridge University Press, Cambridge, United Kingdom and New York, NY, USA, pp. 688.

[3] Policy Study, 2009. The Probable Impacts of Climate Change on Poverty and Economic Growth and the Options of Coping with Adverse Effect of Climate Change in Bangladesh. Support to Monitoring PRS and MDGs in Bangladesh [A. Rahman, M. Alam, K. Mainuddin, M. L. Ali, S.M. Alauddin, M. G. Rabbani, M. M. U. Miah, M. R. Uzzaman, S. M. A. Amin (eds.)], General Economics Division, Planning Commission, Government of the People's Republic of Bangladesh and UNDP Bangladesh.

[4] Alam, M. and Murray, L. A. (2005). 'Facing up to Climate Change in South Asia', The Gatekeeper Series 118, International Institute for Environment and Development (IIED), London, UK.

[5] Rial, J. A., Pielke, Sr. R., Beniston, M., Claussen, M., Canadell, J., Cox, P., Held, H., Noblet-Ducoudré, N. D., Prinn, R., Reynolds, J. F. and Salas, J. D. 'Nonlinearities, Feedbacks and Critical Thresholds within the Earth's Climate System', Climatic Change 65: 11-38, 2004.

[6] Schellnhuber, H. J.: 1999, 'Earth System Analysis and the Second Copernican Revolution', Nature 402, C19-C26. 
[7] Greiner, A., Grüne, L. and Semmler, W. 2010. 'Growth and Climate Change: Threshold and Multiple Equilibria', Dynamic Systems, Economic Growth, and the Environment, 12: 63-78, Springer Berlin Heidelberg.

[8] Sarwar, M. G. M., 2005. 'Impacts of Sea Level Rise on the Coastal Zone of Bangladesh', Masters Thesis, Lund University International Masters Programme in Environmental Science, Lund University, Sweden, 2005.

[9] Henderson-Sellers, A., McGuffie, K., 'A Climate Modelling Primer', John Wiley, Chichester, 1987.

[10]. Biswas, M. H. A. 2014. On the Evolution of AIDS/HIV Treatment : An Optimal Control Approach, Current HIV Research, 12(1): 1-12.

[11] Zell, R. 2004. Global climate change and the emergence/reemergence of infectious diseases, Int. J. Med. Microbiol., 293, Suppl. 37, 16-26.

[12] Patz, J. A. and Olson, S. H. Climate change and health: global to local influences on disease risk, Annals of Tropical Medicine \& Parasitology, Vol. 100, Nos. 5 and 6, $535-549$ (2006)

[13] Geri, P. Yacoubi, S. El and Goyet, C. Forecast of Sea Surface Acidification in the Northwestern Mediterranean Sea, Journal of Computational Environmental Sciences, Volume 2014, Article ID 201819, pp. 1-7.

[14] Nordhaus, W. D. An Optimal Transition Path for Controlling Greenhouse Gases, Science, 258: 1315-1319 (1992).

[15] Biswas, M. H. A., Paiva, L. T. and de Pinho, M. d. R. (2014). A SEIR Model for Control of Infectious Diseases with Constraints. Mathematical Bioscience and Engineering, 11(4): 761-784, 2014.

[16] Agarwal, M and Verma, V. (2012). Modeling and Analysis of the Spread of an Infectious Disease Cholera with Environmental Fluctuations, AAM: Intern. J., $7(1): 406-425$.

[17] Rodrigues, H. S., Monteiro, M. T. T. and Torres, D. F. M. (2010). Dynamics of Dengue epidemics when using optimal control, Mathematical and Computer Modelling, 52: 1667-1673. 
[18] Falugi, P. Kerrigan, E and van Wyk, E. Imperial College London Optimal Control Software User Guide (ICLOCS), Department of Electrical and Electronic Engineering, Imperial College London, London, England, UK, 2010.

[19] Pontryagin, L. S., Boltyanskii, V. G., Gamkrelidze, R. V. and Mischenko, E. F. (1962). “The Mathematical Theory of Optimal Processes", John Wiley, New York, 1962.

[20] Sethi, S. P. and Thompson, G. L. "Optimal control theory : applications to management science and economics", 2nd edition. Springer, 2000.

[21] Vinter, R. B. 2000. “Optimal Control”, Birkh“auser, Boston, 2000.

\section{How to cite this article:}

Biswas H A, Rahman T. and Haque N. Modeling the potential impacts of global climate change in bangladesh: an optimal control approach. J. Fundam. Appl. Sci., 2016, 8(1), 1-19 